九州大学学術情報リポジトリ

Kyushu University Institutional Repository

\title{
Hollow Sounds: Toward a Zen-Derived Aesthetics of Contemporary Music
}

Daryl Jamieson

Faculty of Design, Kyushu University

http://hdl. handle. net/2324/4355093

出版情報: Journal of aesthetics and art criticism. 76 (3)，pp.331-340，2018-08-01. American Society for Aesthetics

バージョン:

権利関係 : 


\title{
Hollow Sounds: toward a Zen-derived aesthetics of contemporary music
}

\author{
Abstract \\ To attempt to fill a perceived gap in Japanese aesthetics concerning music, this paper sketches a \\ possible way into conceptualising a Zen- or Kyoto-school-derived aesthetics of contemporary \\ music. Drawing principally on Kyoto-School philosopher Ueda Shizuteru's theories of \\ language's three levels (signal, symbolic, and hollow words), the author proposes a similar \\ distinction between different kinds of musical experience. Analogous with Ueda's analysis of \\ poetry, the oscillation of signal or symbolic sound and hollow ones is found to be what gives \\ certain contemporary music its spiritual power. By applying this poetic-religious theory of \\ language to music, an entirely new way of understanding contemporary music becomes \\ apparent. As test case of this new approach, Morton Feldman's 1970 work The Viola in My Life \\ (2) is analysed. The final section addresses the differences between this method of understanding \\ via nothingness and traditional Idealist approaches via the Absolute. \\ Keywords: Kyoto School, Ueda Shizuteru, Morton Feldman, Jonathan Harvey, aesthetics of \\ contemporary (atonal) music
}




\section{Hollow Sounds: toward a Zen-derived aesthetics of contemporary music}

Despite more than a millennium of philosophical inquiry into art, Japanese aesthetics has been remarkably quiet on the subject of music. Not completely mum, of course, but in comparison with the other major art forms - especially poetry, but also painting, theatre, architecture, flower arrangement, and even tea, which have all been treated with lengthy essays, books, and scholarly debates down the centuries - music has been almost ignored. Not ignored as a practice, of course; as with almost all human cultures, music is central to life in Japan. In pre-modern times, music was performed in the pleasure quarters, in nō and kabuki theatres, by Buddhist monks, and at Shintō festivals, and in the present, background music is as all-pervasive in Japan as in any other post-industrial country, while the continued prevalence of concert-going, CD-buying, and singing in karaoke boxes all indicate that music has a significant role in Japanese society. Thus the relative lack of theorising about music seems odd, given the generally high degree of importance that aesthetics has had among Japanese thinkers down the ages. ${ }^{1}$

The question of why this has been so is beyond the focus of this paper. Given that this situation does exist, however, what I would like to explore in this paper is the realm of contemporary western art music (concert music, classical music, post-tonal music; it has many possible names) using some of the aesthetic-analytical tools developed by Japanese philosophy, especially by Ueda Shizuteru, one of the most prominent living members of the Kyoto School. By using tools developed for Japanese language and poetry, tools which draw deeply on Zen traditions, I aim to elucidate how a Japanese aesthetic approach might treat 
contemporary music, with the intention that this approach should offer a point of view unique enough to be pursued and developed into what might be called a Buddhist-, Zen- or Kyoto School-inspired aesthetics of contemporary music. ${ }^{2}$

I

What do I mean by 'contemporary' music? For the purposes of this paper, I will be considering music in the non-tonal, non-modal tradition of contemporary music, that which grew out of the modernism of the Second Viennese School and Darmstadt in Europe and Ives via Cage in North America; minimalism, neo-classicism and -romanticism, and other harmonic systems are outside of the scope of this paper, though not outside the scope of my theory as it might develop in future.

Though the principal aim of this paper is to use Ueda's aesthetics to discuss contemporary music, the idea of using language derived from Buddhist philosophy in this manner is hardly a new idea. Famously, the American composer John Cage studied Zen under Daisetsu Suzuki and its influence permeates a great deal of his work. Even earlier, Richard Wagner had been fascinated by what he had learned of Indian Buddhism in his final years. But though neither Cage nor Wagner were ever practitioners of Buddhism as a way of life, there are several western composers who were. Among the most notable is Jonathan Harvey (1939-2012), whose music and writings were profoundly influenced by his practice of Vajrayana (or Esoteric) Buddhism.

Harvey was an ecumenicist who believed in the reality of a spiritual world, one which could be expressed through music, regardless of the faith tradition. He also made a strong theoretical argument that atonal music was the music most able to articulate the spiritual, thus 
defending atonality against a resurgence of tonal and modal references in contemporary music (Harvey 1980, 699). Confident that the limits of tonality were a relic of the Enlightenment era, deserving to be abandoned along with the unquestioning belief in scientific and human moral progress, he also wrote that the nihilistic atonality that pervades the works of Arnold Schoenberg, Igor Stravinsky, Iannis Xenakis, Harrison Birtwistle, Pierre Boulez, and many more of the post-war era - music which so many audiences find off-putting - was a psychologically-necessary but short-lived blip in the historical development of atonal music. Following the cleansing post-war apotheosis of violent soundscapes in the 1950-60s avantgarde, music was free - is now free - to develop the spiritual side of atonality: static, without harmonic movement, without direction; akin to a free-floating, body-less, deathless spirit (Harvey 1980, 699).

Thirty years later, in an article written two years before his death in 2012, Harvey revised his vision of the spiritual in music, identifying it more broadly with the metaphorical dissolution of the world as it is perceived (a strong theme or musical idea) into emptiness and nothingness (variations or developments which reveal the solidity of the original theme to have been an illusion) (Harvey 2017). For Harvey, composition was like a meditation: over the course of years of meditation practice, one learns to identify the 'self', and then realises the essential non-existence of the 'self', or rather, its identity with the universe as a whole; likewise, a musical theme, motif, or cell (depending on the compositional approach) is established and, through constant - often, in Harvey's own music, electronically assisted fluctuation, transformed. 'The joy of composing lies in the dissolving of strong ideas,' he wrote; 'one must have both form and emptiness' (Harvey 2017, 322). 
Thus it can be said that Harvey's Esoteric Buddhist ideal of music is one which is atonal, static, and non-directional (in order to best articulate the spirit realm), and which employs then destroys strong motifs as a metaphor for the practitioner of meditation's dawning understanding of the unreality of the general human perception of the world and the truth of the pure emptiness (śūnyatā) of Buddhist thought. It was with this understanding that Harvey wrote his late masterworks, including Bird Concerto with Pianosong (2001), his Buddhist-inspired 'Glasgow' trilogy for orchestra Body Mandala (2006), Speakings (2008), and ...towards a Pure Land (2005) $)^{3}$, and his final opera Wagner Dream (2006).

\section{II}

The Kyoto School of philosophers came to a similar place from the opposite theological perspective as Harvey; almost all of them with deep knowledge of Zen, but studying Meister Eckhart and Martin Heidegger, and working on Buddhist-Christian interfaith issues. Nishida Kitarō (1870-1945) was the founder of the school, and his most prominent student was Nishitani Keiji (1900-90). Their work has been characterised as 'Japanese Philosophy in the world', a multigenerational effort to transpose Mahāyāna Zen concepts into the more universal language of European philosophy, especially the continental strain of philosophy centred on Heidegger, with whom several of the Kyoto School philosophers studied (Davis 2017).

Though the Kyoto School is far from monolithic in its thought, one core tenet they share is the Mahāyāna (and Dao) conviction that nothingness is the ground of all existence. This is in marked contrast to European philosophical traditions, which grew out of poly- and monotheistic traditions with a God or gods - Being or the Absolute - as its ground. The Kyoto 
School's nothingness is a positive, creative force, which, in Ueda Shizuteru's phrase, moves 'from nothingness' toward Being, while Friedrich Nietzsche, Heidegger, and the deconstructionists were moving from Being 'toward nothingness' (Ueda 2011b, 29). Though each of the principal philosophers in the Kyoto School has a slightly different view of the void - Nishida coins the term 'absolute nothingness' to distinguish it from the negative Western conception of a lack of Being (nihilism); Nishitani appropriates the traditional Buddhist term 'emptiness' ('́änyatā) - all hold with the Mahāyāna Buddhist idea of it being the ground of all things.

The outstanding Kyoto School philosopher of the third generation, Ueda (born in 1926) has made language and its role as a conduit between our human perception of reality and the limitless nothingness which envelops us one of the principal concerns of his thought. As with his predecessors Nishida and Nishitani, and drawing on sources as far back as Meister Eckhart's 'breakthrough to the nothingness of the Godhead' in the Christian mystical tradition (Ueda 1991, 158) and the 2nd century Indian Buddhist philosopher Nāgārjuna's conception of nirvāna not as an escape from the actual world, but 'rather an enlightened manner of being-in-the-world here and now' (Davis 2017), Ueda posits a limitless, absolute nothingness in which the world (meaning the entire perceivable universe) is situated, which he terms the 'hollow-expanse' (Ueda 2011a, 776).

According to Ueda, our picture of reality, our 'actual' world is created entirely through the medium of language, and words spoken, read, or thought express and 'manifest' matters and things. ${ }^{4}$ This 'manifestation' occurs in the mind of the listener/reader/thinker of words; a word perceived generally disappears as a word and is received not as a 'word' but as a 'thing' (Ueda 2011a, 774). For example, if I direct your attention to the lone word 'moonlight', 
you will probably perceive that as an image, a constellation of sensations, memories, and/or feelings - but not as a two-syllable, nine-letter artefact of language/text. The word as a word disappears, and the actual 'matter' - the moonlight - manifests itself in your mind. ${ }^{5}$

Language has this power to manifest actual matters - objects and events which exist in the everyday world of our reality - but it also has the power to manifest things which do not exist in the everyday actual world. Ueda calls these things hollow things, things which 'can only be expressed with language and ... exists only within language' (Ueda 2011a, 774). One example that Ueda offers of hollow language is 'a man crosses a bridge, and the bridge flows while the river does not.' Unlike the 'moonlight' example, the unreality of the image of the flowing bridge draws attention back to the words, and thus the language does not disappear. The image is 'hollow', still tied to language. This pair - 'actual' and 'hollow' - are both necessary for communication, especially any artistic, religious, or creative language. They articulate what Ueda calls a 'twofold being-in-the-world' (with a debt to Heidegger's being-inthe-world), the twofoldedness referring to the interpentration of the 'actual world' as perceived in everyday life by the true reality of the nothingness/hollow expanse.

Ueda defines three levels of language which together contribute to the articulation and manifestation of our twofold world. They are the language of signs, symbols, and hollow language. Signs manifest objects, for example the word 'moonlight' functions as a sign as detailed above. Symbols manifest events - things which are bigger than the words themselves and can encompass up to all of what our standard level of human perception allows us to perceive. In other words, symbols are the mainstay of everyday linguistic expression of things in the 'actual' world. 'My empty boat' is a combination of three signs, which together suggest more than simply those signs: they suggest a story, and perhaps some questions (Why is your 
boat empty?). Signs manifest objects in the perceivable world, and symbols create the narrative that allows us to understand and be in that world.

Hollow words, however, release us from what is called reality and allow us to glimpse the limitless nothingness that is normally beyond our perception and which is literally inconceivable in terms of language. Language - including hollow words - can never describe the hollow expanse that encompasses the world; by rupturing our conception of reality, hollow words allow us to sense the absolute emptiness behind the veneer of human language and the perception we call reality. As Ueda explains, 'what one has a sensation of is spoken spoken of as an actual matter [in signs and symbols], and what one has a sense of is spoken of as a hollow thing' [italics in the original] (Ueda 2011a, 776). An old Zen saying (though hollow words are not in any way limited to Zen: they encompass fantasy, the absurd, punchlines of jokes, poetry, and much else) is used by Ueda to demonstrate the relationship between actuality and hollowness: 'I loaded my empty boat full of moonlight / and came home.' The actual facts of the matter - an unsuccessful fishing trip, perhaps - are hollowed out, and through a realisation of the true nature of the twofold (actual/hollow) world, I become 'full' of emptiness. Spiritually and intellectually speaking, this insight is more fulfilling than the transient satiety of a few fish (Ueda 2011a, 782).

Ueda has written about language as it is written or spoken, and though most of his examples of how art has the potential to open up the hollow-expanse are linguistic, he does recognise that other arts or a profound experience of nature could equally open up a glimpse of the hollow world (in the Zen example above the hollow phrase serves to record an insight which seems to have been brought about by contemplating the moon). Other philosophers have tackled other art forms - Nishitani wrote elegantly about ikebana, flower arranging 
(Nishitanai 2011) for instance - and elucidated how they tread the line between the perceived world and the emptiness at its root. It is my contention that Ueda's linguistic model provides a strong basis for beginning to think in this way about music, and how music might also act as a bridge between formlessness and form.

\section{III}

The view that literature, religion, art, or nature have the potential to unlock the mysterious, unknowable world which lies just beyond the limits of our perception was also held by the German Idealists - E.T.A. Hoffmann, Friedrich Schlegel, Joseph von Schelling, Ludwig Tieck, among others. Their Ideal was Being, the noumenal, the Absolute, the opposite of nothingness as conceived by Buddhism and the Kyoto School. Hoffmann, for instance, championed instrumental, non-programmatic music as 'spiritual absolutism'; in his famous 1810 article praising Beethoven, and above all his then two-year-old Symphony No 5, Hoffmann writes that music's 'only subject matter is infinity... Music reveals to man an unknown realm, a world quite separate from the outer sensual world surrounding him' (Hoffmann 1998, 96).

In contrast to the German Idealists, $20^{\text {th }}$-century American composer Morton Feldman insisted that most music was metaphorical (Feldman 2006, 35) and very little was abstract sound. ${ }^{6}$ I am inclined to agree with Feldman; 'hollow sound' could be one name for sound which either does not reference other sound (i.e. completely original sound) or unique combinations of commonly-known sounds, such as those Feldman wrote. But hollow sounds cannot just be those; like absurdist, surreal, or magically real art and writing, sounds or music which shock through the subversion of generic conventions should also be considered hollow, 
in that they open the mind to the unexpected. As Ueda wrote, '[c]ontravening the nihilistic desertification within the world that results from a toxic excess of meaning, such nonmeaningful words stir up the world and, supplying it with fresh air, promote a regeneration of meaning' (Ueda 2011a, 777). So music which likewise 'regenerates' and expands the conventions of a genre should also be considered 'hollow'.

Signs and symbols are more difficult to define. Musique concrète seems unambiguous; a recorded sound is almost certainly a sign of that which was the source of the recording - at least until the recording is manipulated, at which point it takes its place either as part of a musical narrative or discourse (and thus becomes a symbol) or it is somehow subverted (and thus becomes hollow). There are percussion instruments (the anvil, the thundersheet, the lion's roar) whose names give away their predominantly signifying function; likewise, a horse's whiney can be effectively imitated on a trumpet and birdsong on flutes and clarinets. Other examples abound in the long history of musical word painting and programme music.

But these representations are not unambiguous: as with poetic words and phrases, context matters. Are the onomatopoeic storm sounds in Beethoven's Symphony No 6 signs (a truthful representation of a thing which, in the hearing and understanding, effectively manifests the thing itself) or symbols (which metonymically represent an aspect or the whole of reality)? We can learn the classical musical vocabulary of storms (fast falling scales, thunderous percussion, minor or dissonant harmonies), and though one coming to classical music for the first time may well not recognise the storm in Beethoven's Symphony No 6 as a storm, in this musical languages are no different from spoken ones; an English monoglot may well get a hint that Sturm is German for storm just as a classical music novice might glean that a thundersheet represents a thunder storm, but that same English monoglot would fail to 
recognise arashi as meaning storm in Japanese, but that in no way takes away from the word arasbi's function as a sign within the Japanese language itself, and likewise a baroque wordpainting convention or Wagnerian Leitmotif might not be able to be intuitively understood on its first hearing, but once learned, a sign - linguistic or musical - is a sign, and can then be manipulated into becoming a symbol or hollow sound. The answer, then, is with the listener, not the composer: the listener's level of familiarity with the piece and its genre will determine whether or not they can move beyond hear the sounds as signs and be able to link individual sounds into a symbol within a coherent narrative. Instances of musical parody, as well as allusions to or quotations of other pieces within a piece can equally be sign or symbol depending on both the context and the listener.

Like individual words, individual sounds also function as signs. A standardlyperformed trumpet note signifies a trumpet playing; likewise the four members of a string quartet playing is by itself a timbral sign of a 'string quartet'. Musical signs can be what Eric F. Clarke in his seminal book on the ecological approach to musical perception, Ways of Listening, calls invariants'. In his discussion of the first eight bars of Beethoven’s String Quartet Opus 132, he identifies 'minor mode', 'motet-like homophony', 'registral expansion', and 'uncadenced ending' as invariants (Clarke 2005, 176), which operate similarly to Ueda's signs. They are identifiable features of the music which simply manifest themselves when they are heard. We hear a string quartet, and we perceive a string quartet; we hear a piece in the minor mode and we recognise it as minor, etc, in the same way the nine letters of the word moonlight are read and an image/concept of moonlight is manifested in our minds.

Furthermore, as linguistic signs are put together to create narratives and wider meanings, and thus operate at the level of symbol (symbolising things, events, and concepts within our 
experience of what we call everyday reality), so these musical signs (or invariants) are combined to suggest a wider narrative: the 'tragic' minor, 'religious/spiritual by association; calm and patient by virtue of tempo and pitch profile' homophony, the 'seeking/exploring' expansion, and the sense of an 'unended quest' in the uncadenced ending all combine to suggest a 'questing and tragic spirituality' (Clarke 2005, 175-6). This is music being listened to at the symbolic level, signs being combined to mean (or suggest one among possible meanings) something greater than the sum of the signs themselves, which Clarke calls a musical topic. ${ }^{7}$ What Ueda's three-part classification adds to Clarke's ecological approach to topic theory is the idea of hollowness, which accounts for the transcendent, luminous quality that the Romantics and many since identify in absolute music (and other genres too). When signs and symbols are combined in a way that does not reflect our expectations of reality, does not correspond to what we think we know - when they shock or move us mentally into a new place of awareness - then the sounds have become hollow; what were signs and symbols have been hollowed out and 'filled with emptiness'.

Thus we can see that, like spoken language, music can and does operate on the three levels of signs, symbols, and hollow sounds, and, indeed, the same musical pattern can shift from one level to another depending on its context and the listener's familiarity with the piece or genre. The question then becomes, which pieces, which ways of composing are adept at illustrating the crack between the experienced world and the void and thus capable of expressing deep spiritual meaning?

At the beginning of this paper, I outlined Jonathan Harvey's answer to this question: to write music that simply 'is' in the moment, to avoid teleological forms and harmonies, to pursue the composition of music which is radically aware of the real world and the void 
underpinning it. This meant for him a music of post-Webernian atonal harmony (a harmony without a root, whose ground is nothingness), where strong themes dissolve into emptiness. Bird Concerto with Pianosong for instance, in which the recorded sounds of birds (signifying sounds) are electronically manipulated (becoming-hollow sounds) and blend seamlessly with flutes and oboes producing their own variations on birdsong (symbolic sounds). The three types of sound/language work together to (in order) manifest for the listener the mental image of birds, then to radically subvert that image, and finally to replant the idea of birds metaphorically in the woodwind section, thus connecting the aware human observer/listener with the universe as a whole, while also giving them a vertiginous glimpse into the unknown on the way.

Harvey's notion of theme/transformation/dissolution, which he connects to the personal experience of meditation, in which the self is identified and then overcome over many years of just sitting, can itself be universalised using Ueda's linguistic framework. Of course, as a composer, Harvey's ideas are musically more relevant, and thus gives the composer so interested a set of aesthetic tools they could use in their own quest to write non-teleological, spiritual music. These tools avoid the clichés of spiritual music (as, indeed, clichés must be avoided, as parody cannot itself rise above the symbolic level) in that they are not uniformly slow, empty, quiet, modal, or militant; nor are most of them even theological. Harvey is thus a model composer of spiritual music, one who lived up to his own high aesthetic and spiritual ideals. 
However, an appropriation of Ueda's linguistic system for musical-aesthetic purposes would itself have little purpose if it could only be used to speak about Buddhist or Zen music, or only about specifically spiritual music, or, indeed, only about music from East Asia.

Therefore, I will discuss the work of another composer, Morton Feldman, whose music is widely considered to rank among the greatest of the post-war period. He was a composer who had a passing familiarity with Zen, through his close association with John Cage, but was never a student or practitioner of it. He was a Jewish New Yorker, and a professed believer in the Jewish God, though he largely kept his faith a private matter (Levy 2103, 571).

I mentioned above that Feldman's late period, from about 1979 onwards, saw him mostly writing works in excess of one hour. These extended durations gave him the chance to engage in the creation and subsequent subversion of a unique musical world in every piece. At this time he made a point of writing almost exclusively for traditional ensembles, the timbral familiarity of these ensembles helping listeners by giving them recognisable signs. Those signs are arranged in a thoroughly unfamiliar and often disjunct, fragmented way that initially resist understanding. By the end of an hour or more in Feldman's soundworld, the sounds have become normalised, but never lose their fragmented quality, and never repeat exactly; they cross over into the symbolic by the listener's increasing familiarity with the piece's soundworld, but refuse to settle into predictability. In this way he achieves a delicate balance of signal, symbolic, and hollow. Often, just at the point when we believe ourselves to be comfortable and the hollow sounds are are becoming normalised, new material enters the work which again subverts our expectations, catapulting us into the hollow-expanse one final time, more surely and effectively than before. As an example of how this might work on a small scale, without the familiarity of a standard ensemble or the length with which to become 
fully accustomed to the piece's soundworld, I would like to take a close look at Feldman's The Viola in My Life (2) (1970) for solo viola, flute, clarinet, percussion, celesta, violin, and cello. It's a middle-period piece, about ten minutes in length, quite sparse and quiet. It could be structurally divided in many ways, but there is an obvious change in mood at the $118^{\text {th }}$ bar, and for the purposes of this discussion I will refer to bb. 1-117 as the first part, and bb. 118187 (the final bar) as the second part. Though there are audible differences between the two parts, I would not characterise them as 'contrasting', and they thus do not function in the way classical A-B forms do.

While not written for a standard classical ensemble, it's instrumentation is not too unusual; it's a variation of the Pierrot Ensemble (flute, clarinet, piano, violin, and cello), which became a standard $20^{\text {th }}$ century ensemble after Schoenberg used it in his groundbreaking 1912 work Pierrot lunaire. The addition of percussion to the group became fairly standard in the second half of the $20^{\text {th }}$ century, while substituting a celesta for piano was less so. Using the ensemble to accompany a viola (or any) soloist is unusual. Thus, despite the familiar instruments played without any extended techniques, we are immediately in a somewhat unfamiliar (but far from unprecedented) soundworld merely by virtue of the instrumentation.

Our expectations are also thwarted by the opening bar of silence ${ }^{8}$ and the very quiet staggered entrances of the six musicians who play in bar two. These staggered entrances disrupt any attempt to hear the pulse, which is, in fact, unchanging but almost inaudible throughout the piece. The argument of the piece as a whole can be thought of in a variety of ways, one of which is a deconstruction or dissolution of the opening soundworld, a basic movement from sound to silence, from many to one - and then none. Following that opening bar of silence, there is not a full bar of silence again until b. 49 , more than a quarter of the way 
through the piece. From there, however, the silences build up - a crescendo of silences - with 15 full bars of silence in the second section of the piece. Likewise, instances of ensemble playing diminish as the piece progresses, starting with that initial group of six in b. 2 and continuing with various permutations of ensemble until bb. 61-4, when the viola has its longest unaccompanied solo passage. Unaccompanied solo bars (bb. $61-4$ is the longest 'passage') gradually increase towards the end, comprising 50 out of the 187 bars of the whole piece $(27 \%)$ and 24 of the second section's $70(34 \%)$. So the preponderance of bars in which there are either no instruments or only one instrument playing are in the second section, while the final time that all seven players play in the same musical system is at bb. 79-84. The full seven member ensemble never play simultaneously at any point in the piece, so in the sense of silence being a player not playing, there is never not a silence throughout the whole piece; but clearly the amount of silence (no sound being produced at all) and tacetness (individual instrumentalists not playing) both increase as the piece progresses. From the perspective of a listener without access to the score, one can hear that the density of instrumental colour (in other words, the number of different instruments which are playing simultaneously or within a defined period of time) decreases reasonably steadily over the course of the piece.

This dissolution is most marked in the celesta part, which functions as a kind of punctuation. It usually enters at the end of a phrase, symbolising a change in texture or motif. Though mostly accompanied by other instruments, until b. 108, the dense celesta clusters dominate the texture every time it is played. When two or three celesta clusters occur in a row (such as at bb. 35-50, 68-70), they have the effect of continuous interruptions which prevent the progression of the material; they hinder; they disrupt. Bar 89 is the last time the celesta plays a cluster, and from this point to the end of the piece, it plays only one pitch class at a 
time. The disruptive cluster effect is taken on by other instruments (sometime with the celesta and vibraphone providing a metallic timbral element to the texture, and sometimes not). The celesta does not play at all in the final 50 bars of the piece.

In terms of pulse and metre, too, there is a process of dissolution which occurs over the course of the piece. In some ways this is only conceptual: the opening sounds pulseless to the audience, and only the musicians know what the pulse is. That said, Feldman chooses to write the first half of the piece (bb. 1-98) in triple time, only once deviating from 3/4 time for a single bar of $3 / 2$ (which is essentially a hemiola rather than a change of metre). From b. 99, the time signature changes frequently, shifting irregularly between duple, triple, and compound time. While from the point of view of the musicians this means that the pulse is less regular, the nature of the material in the second half of the piece is such that the beat is more audible to the listener. So the conducted pulse and the heard beat move in opposite directions over the piece, both of their starting positions transforming.

What does this mean in terms of Ueda's three levels, and how does this piece achieve it's feeling of otherworldliness, it's glimpse into the hollow expanse? The first section is hollow in terms of lack of pulse and timbral combinations; it's hollow in a beautiful, ethereal sense, like a magically real painting or the eternal emptiness revealed in a cut (dying) flower in ikebana (Nishitani 2011), not in a shockingly disruptive sense, like Nansen cutting a cat in half. ${ }^{9}$ The viola's prominent position functions as a guide for the listener, giving them something to grasp, a 'way in' - one possible way for a listener to construct a narrative and hear the piece on a symbolic level, rather than as a collection of unlinked signs. Due to the much shorter length of this piece compared with his later works, the audience is not as thoroughly familiarised with this material as it can become when listening to his late-period 
pieces, nonetheless as the rests and tacets build up in the second half of the first section, we can recognise the fragmentation that is occurring - thus confirming the material being fragmented as symbolic, something we have taken in to ourselves and related to our world. The second section introduces a modal melodic fragment in a standard viola range: a symbol that is made up of several signs, in that it connects to tradition and memory via the simplicity of children's and/or folk songs, its standard playing techniques, and its modal (not atonal) character. As it too is broken up, we can perceive the crack between us and the hollowexpanse more strongly than with the previous statement-dissolution pair in section one. The ending - long vibraphone notes interrupted by viola irregularly-spaced pizzicato chords represents the final dissolution of the celesta part (the metalophone part) which has been running as a countertheme throughout the piece. From large clusters in the first section diminishing to single tones in the second, in this coda, even the continuity of a sustained pitch becomes subject to disintegration through the slow pulsation of the vibraphone's motor. Here too the viola's role disintegrates, from leader to accompanist. Feldman leaves us alone, without guidance, in silence, staring into the absolute nothingness.

\section{V}

One key difference between Buddhism and the Abrahamic monotheisms is that the Abrahamic heaven (which is at the root of such concepts as the Absolute and noumenal) is a place which exists eternally and is separate from our world, while the Mahāyāna nirvāna is 'an enlightened manner of being-in-the-world here and now' (Davis 2017). The nothingness of the 'other world' is surrounding and interpenetrating the 'actual' world; there is no other place 
to go to, since the other world is in fact empty and as impermanent as the actual one. The Idealist writer and critic Ludwig Tieck 'strenuously disavow[ed] any connection of [instrumental music] with the phenomenal world. Instead, he emphasised that musical notes 'constitute a separate world unto themselves'" (Bonds 2006, 23), while Hoffmann said that '[m] usic reveals to man an unknown realm, a world quite separate from the outer sensual world surrounding him' (Hoffmann 1998, 96). This is more than a metaphysical difference without consequence. It affects the way music is perceived, and its relevance to the nonmusical world. If music is perceived as occupying a separate realm, remote from the everyday, one which, in Johann Gottfried Herder's words, requires 'reverent contemplation' (Bonds $2006,25)$ to ascend to, then music will be perceived as irrelevant to our actual world. The Idealists used music as an ecstatic escape from the world, but only a way of listening rooted in the world can have ethical and political meaning for people who are also being in the world.

The focus on Being at the root of Idealist thinking is teleological, and is best suited to teleological musics (whether the telos in question is a tonal home key or a climax workedtowards and achieved by textural or other non-tonal means), and ill-suited to the post-modern ateleological understanding of both the arts and the world. In contrast, a means of understanding grounded in nothingness can explain both teleological and ateleological musics, since the teleological aspect of music is only one of many possible symbols which might be hollowed-out. The constant change of levels of perception between the sound as sign (the sound itself), sound as symbol (one part of a narrative encompassing living things, the natural world and, intertextually, previous artworks), and sound as hollow (through radical innovation in sound or subversion of expectations within a genre), is a circular, ateleological model. This way of listening to music - which could also be a guide to composing it - runs 
counter to Hoffmann's pronouncement that 'the deeper mysteries can never be spoken of in ordinary words... but only in expressions of sublime splendour' (Hoffmann 1998, 102). To the contrary, it is the oscillation between the ordinary and sublime, the actual and the hollow, that gives music its beauty and power. Work which is all mystery, which cannot be understood at least in part as symbol (in other words, as part of a narrative connected to the listener's actual world) cannot but be heard as pure sign, and cannot achieve the hollow register at all. This is the experience for those many listeners who cannot understand the so-called difficult music of the post-war avant-garde; unable to grasp the structure or meaning of anything, they hear only an unending succession of signs (a viola makes a sound, then a marimba makes a sound, then a harp makes some sounds, and on and on, with no sense of how to connect these signal sounds into a symbolic structure or pattern). By aiming to separate themselves from the history of music, the possibilities of intertextuality and generic expectations, by aiming for a pure succession of 'hollowness', those composers held a radical Idealist conception of music's place as completely separate from society and history, and - from the perspective of a great many listeners - in the end closed off the hollow world rather than opened it up. ${ }^{10}$ This is not to say that the post-war avant-garde music was ill-judged; learning the conventions of each composer or group of similar composers, being able to hear symbols in the signs, can of course be done through repeated exposure, and is often very much worth the effort. The potential for a glimpse of the hollow world is certainly there in much of this repertoire, and much of it is sublime. Listeners, however, can be forgiven for not being able to hear the potential for hollow sounds on their first exposure.

Feldman's late-period works avoid this problem through his use of familiar timbres which can be heard as symbolic - and limited musical material - which become symbolic 
through repetitions and extreme length, and are made hollow by irregularity and the introduction of new material. The Viola in My Life (2) and other mid-period works use modal elements and avoid extended techniques, giving listeners a quicker way into perceiving in a symbolic way. Harvey's works present strong, clear musical ideas which are easily assimilable as symbolic and then he gradually dissolves (hollows) them.

For the symbolic to be readily and widely perceived (and therefore, have the potential to be hollowed out), it is clear that the music in question must have some element of the familiar in combination with a subversion of that familiar thing. A balanced approach not a world away from Immanuel Kant's proscription for art: 'To avoid creating the appearance of chaos, works of art would always be obliged to follow certain rules; true art, however, incorporates the unpredictable, indescribable, and ultimately unknowable element of originality' (Bonds 2006, 38). For composers, performers, and listeners who are seeking an understanding of timelessness, directionlessness, and emptiness in music, Ueda's analytical tools, in combination with Harvey's practical observations, provide an excellent place to start for a new way of thinking about the place of music in one's spiritual life. 


\section{References}

Bonds, Mark Evan. Music as Thought: Listening to the Symphony in the Age of Beethoven. Princeton: Princeton University Press, 2006.

Cage, John. Silence. Middletown: Wesleyan University Press, 1961.

Clarke, Eric F. Ways of Listening: An Ecological Approach to the Perception of Musical Meaning. Oxford: Oxford University Press, 2005.

Davis, Bret W. 'The Kyoto School'. In Stanford Encyclopedia of Philosophy. Edited by Edward N. Zalta. Metaphysics Research Lab, Stanford University, 2017: https://plato.stanford.edu/ entries/kyoto-school (accessed 3 August 2017).

Feldman, Morton. Morton Feldman says: selected interviews and lectures 1964-1987. Edited by Chris Villars. London: Hyphen Press, 2006.

Harvey, Jonathan. 'The Composer's View: Atonality'. The Musical Times, 121 (1980): 699-700.

Harvey, Jonathan. 'Spiritual Music: 'Positive' Negative Theology?' In Contemporary Music and Spirituality. Edited by Robert Sholl and Sander Van Maas, 311-25. London: Routledge, 2017.

Hoffman, E.T.A. 'Beethoven's Instrumental Music'. In E. T. A. Hoffmann's Musical Writings: Kreisleriana; The Poet and the Composer; Music Criticism, ed. David Charlton. Cambridge: Cambridge University Press, 1989. Translated by Martyn Clarke. 96-103..

Levy, Benjamin R. 'Vertical Thoughts: Feldman, Judaism, and the Open Aesthetic.' In Contemporary Music Review, 32:6 (2013), 571-588.

Marra, Michael. Essays on Japan: Between Aesthetics and Literature. Leiden: Brill, 2010.

Nishitani Keiji. 'Ikebana'. Translated by Jeff M. Shore. In Japanese Philosophy: a sourcebook. Edited by James W. Heisig, Thomas P. Kasulis, John C. Maraldo. Honolulu: University of Hawai'i Press, 2011: 1197-2000.

Swanson, Paul L. “'Zen is Not Buddhism”: Recent Japanese Critiques of Buddha-Nature'. Numen, 40 (1993): 115-49.

Ueda Shizuteru. 'Language in a Twofold World.' Translated by Bret W. Davis. In Japanese Philosophy: a sourcebook. Edited by James W. Heisig, Thomas P. Kasulis, John C. Maraldo. Honolulu: University of Hawai'i Press, 2011a: 766-84.

Ueda Shizuteru. 'Contributions to Dialogue with the Kyoto School'. In Japanese and Continental Philosophy: Conversations with the Kyoto School. Edited by Bret W. Davis, Brian Schroeder, and Jason M. Wirth. Bloomington: University of Indiana Press, 2011b: 19-32. 
Ueda Shizuteru. '"Nothingness" in Meister Eckhart and Zen Buddhism: With Particular Reference to the Borderlands of Philosophy and Theology'. In The Buddha Eye: an Anthology of the Kyoto School. Edited by Frederick Franck. New York: Crossroad, 1991: pp157-68.

Ueda Shizuteru. Kotoba. Tokyo: Iwanami Shoten, 2008. 


\section{Endnotes}

${ }^{1}$ Of course, there are some exceptions. Moroi Saburō, a composer associated with the Kyoto School, comes closest to being a musically-engaged philosopher, but his philosophical contributions are nowhere near the level of his Kyoto School associates, or of the European musically-oriented philosophers such as Adorno, Schopenhauer, Nietzche, and Kant, among many others.

2 I separate 'Buddhist' and 'Zen' deliberately here, and throughout the paper; there is some disagreement among religious scholars about whether Zen is a sect of Buddhism, or a separate religious offshoot (Swanson 1993, 115-49).

${ }^{3}$ The stated order of the trilogy is correct despite the dates being out of order. See: http://www.fabermusic.com/ news/jonathan-harveys-masterpiece-trilogy-at-edinburgh-international-festival-252 (accessed 9 April 2017)

${ }^{4}$ This idea has a distinguished pedigree in Japanese aesthetics, going back at least to the 12th century Japanese poet Fujiwara Shunzei, who used Tendai Buddhist teachings to posit that the world is not perceived directly, but rather through language, specifically the language of poetry (Marra 2010, 65-6).

${ }^{5}$ Seeing a specific instance of moonlight which falls within the bounds of your understanding of 'moonlight' with your own eyes would cause the same process to unfold. The photons of light which reach your eyes are not what you perceive any more than the letters of the word - the external phenomenon dissolves, and an image is created in your own mind.

${ }^{6}$ Feldman's own music, as well as his friend Christian Wolff's, was unsurprisingly identified as not metaphorical.

${ }^{7}$ Clarke discusses topic theory and its principal formulators and supporters in depth in (Clarke 2005, 159-76).

8 This unexpected silence would wrong-foot an attentive listener even if they have no access to the score, either in a live performance with the visual cues of a conductor starting the piece but no sound forthcoming, or on CD, when the track begins to play but no sound can be heard - assuming that the record label has left the silence intact, of course. Additionally, I have chosen to restrict my discussion to the score, using bar numbers rather than timings in part for reasons of clarity. There are several fine recordings of this work available and I have no reason to favour one over any others.

${ }^{9}$ A classic Zen kōan in which Zen Master Nansen Solomon-like mediates between two groups of monks claiming the same cat; unlike the story of Solomon and the baby, Nansen goes through with cutting the cat in half (Mumonkan [The Gateless Gate], case 14).

${ }^{10}$ On the other hand, music which does not innovate, which recycles familiar harmonic systems, familiar genres, and familiar sounds, stays so firmly rooted in the symbolic for most listeners that a glimpse of the hollow world also becomes impossible. 